representations of each constellation, I'd be first in the queue with my money.

The transition between star maps, the beautiful, and star maps, the functional tool of modern science, is illustrated perfectly by the second book under review. Papadopoulos has produced a large set of maps by photographing the sky through a four-element astrographic objective lens manufactured by Carl Zeiss (Oberkochen). This lens had a diameter of $12.5 \mathrm{~cm}$, a focal length of $62.5 \mathrm{~cm}$ and gave a negative with a usable field of $15^{\circ}$. Each map has been produced from the original negative by line reproduction, a system which prints only black, and has no halftones. This is ideal for stars but gives a very poor reproduction of the appearance of galaxies and nebulae.

The Southern Stars volume contains 120 maps covering the sky region from declination $-30^{\circ}$ to the South Celestial Pole. Each map covers an area of $11^{\circ}$ by $11^{\circ}$ and there is a minimum overlap of at least $1^{\circ}$ between neighbours. The Equatorial Stars volume contains 216 maps and covers the region between $-30^{\circ}$ and $+30^{\circ}$ in declination. A set of transparent co-ordinate overlays are provided, six for Vol. 1 and three for Vol. 2 . The system is converted to 1950.0. Each map measures about $33 \mathrm{~cm}$ by $33 \mathrm{~cm}$. Volume 3, Northern Stars, will be published later this year.

The atlas is designed to show all stars which are brighter than visual magnitude 13.5 and, to quote the author, "the final print produces star images with easily readable differences in their diameters according to their magnitude". The accuracy with which the magnitude can be assessed obviously depends on the accuracy with which the star image diameters have been produced on the map and on the accuracy of measuring these diameters (a star of third magnitude is about $1 \mathrm{~mm}$ across). Superficially each map appears like a white sheet speckled with tiny black dots, surrounded by a black border with right ascension and declination markings on them so that the transparent grid can be positioned. To find your way between maps you are given a rather inadequate, small-scale, chart index. You actually need at least a copy of Antonin Bečvár̆'s Atlas Coeli and preferably a set of Smithsonian Astrophysical Observatory star charts as well. The main advantage of the Papadopoulos atlas is that it goes down to visual magnitudes 13.5 as opposed to the SAO which stops about ninth. The main disadvantage is the price, but assuming you need to go down to $13.5 \mathrm{mag}$ (and I would be very surprised if the number of astronomers who do really need to do this is more than miniscule) $£ 245$ for a collection of 336 Papadopoulos maps - Vols. 1 and 2 - is what you have to pay here. I must confess that I won't, and neither will my university.

David W. Hughes is Lecturer in Astronomy and Physics at University of Sheffield, UK.

\section{Thriving young discipline}

\section{Martin Daly}

Human Sociobiology: A Holistic Approach. By D.G. Freedman. Pp.192. (Free Press/Collier Macmillan: New York and London, 1979.) £8.50. The Genesis Factor. By R.A. Wallace. Pp.256. (William Morrow: New York, 1979.) $\$ 9.95$.

HUMAN sociobiology seems to be a thriving young discipline, if a spate of books and new journals over the past two years is to be taken as evidence. Perhaps much of this activity will eventually be seen to be the cloaking of old ideas in new jargon, but much of it is truly synthetic. Sociobiology is gaining adherents among social scientists because, rather than contesting their established theoretical approaches, it is for the most part metatheoretical to their usual levels of analysis. Theories of sex role socialization, for example, may accurately describe processes by which masculine and feminine behaviour develop, while offering no insight into the cross-cultural consistency of the outcomes. Or a potlatch may be explained as a status competition, while taking it as a given that status is a commodity for which men will find it reasonable to compete. Sociobiological theory attempts to deal with some of the questions that structural, descriptive theories of human action fail to address.

If a "new synthesis" can indeed be said to be emerging, it is not surprising that anthropology, the social science most informed by evolutionary thought, is leading the way. However, sociobiological schools of thought have also surfaced in economics, sociology and even political science. The laggards whose participation is most seriously missed are psychologists.

The grounds for thinking psychology a crucial missing element in a productive synthesis are as follows. Anthropologists and other scientists testing sociobiological hypotheses have been concerned to demonstrate measurable fitness consequences of extant variation in behaviour, and they have achieved some notable successes (see, for example, chapters in Evolutionary Biology and Human Social Behavior: An Anthropological Perspective, edited by N.A. Chagnon and W. Irons; Duxbury Press, 1979). However, a good deal of modern human behaviour is manifestly not fitness-maximizing. Must sociobiology therefore be mute about its origins? Not if appropriate models of the structure of human motives and cognitive processes can be developed. The psychological mechanisms proposed must be anchored simultaneously in sociobiological accounts of their phylogeny and adaptive significance and in predictions of their behavioural outputs, including predictive statements about the kinds of circumstances in which such evolved mechanisms can be expected not to produce adaptive outcomes. This task offers experimental psychologists a gold mine of opportunity for research and for theory development.

Daniel Freedman's Human Sociobiology: A Holistic Approach constitutes an early psychological foray into this rich field, and while the effort is deeply flawed, it nevertheless unearths several nuggets. The book's greatest shortcoming resides in the fact that Freedman ventures out of his depth in population biology. This produces two extremely distracting muddles. One, which surfaces repeatedly, concerns the significance of populational levels of heterozygosity. Freedman imagines that inbreeding is selected against not because of any deleterious effects of homozygosity upon the offspring of consanguineous unions, but because it constitutes "bad evolutionary planning" by reducing populational reservoirs of heterozygosity. He proceeds from this basic misunderstanding to characterize human populations as more or less heterozygous according to their marriage practices, a train of speculation which in Chapter 7 leads to several odd conclusions which leave the author needlessly vulnerable to accusations of racism.

The second major muddle is conceptually related to the first. Freedman has borrowed his University of Chicago colleague Michael Wade's suspicion of

\section{MESOZOIC MAMMALS}

\section{The First Two-Thirds of Mammalian History}

\section{Edited by Jason A. Lillegraven}

Mammals have been an important part of the earth's land fauna for at least 200 million years. This book offers a comprehensive review of what is known about mammalian life during the first twothirds of its history - the Mesozoic era before the extinction of the great reptiles. The book provides biologists and geologists with encyclopedic listings of fossil locations, recognized taxa, and temporal-geographical occurrences of genera along with descriptions of the anatomical features of each group and extensive bibliographies. Interwoven with the summaries of data are valuable interpretive - sometimes admittedly speculative - discussions of the origins of mammals, their patterns of distribution, and their biological, behavioral, and evolutionary relationships during the "dark ages" of mammalian history. Illus. 320 pages $£ 21.00$, cloth $£ 5.75$ paper.

\section{UNIVERSITY OF CALIFORNIA PRESS}

2-4 Brook Street, London W1. 
"selfish gene" reductionism without apparently grasping the rationale for that suspicion. The undisputed fact that social groups have complex interactive properties which may be mistaken by researchers focussing attention on individuals is thoroughly confused with the question of the roles of group versus individual selection in the evolution of adaptation. I am not cavilling on this subject, for the author's imagined critique of individual selection is a major, recurring theme of the book. He begins Chapter 4 with this paragraph (page 45):

I hope I have by now established that both the selfish-gene approach from below and the group selection approach from above are needed for an adequate explanation of social behavior, no matter the species. When we get to primates, the need for a dual causality model rather than a one-way model is emphasized since primates can act with clear selfishness or in concert, as the situation demands.

By this point, sociobiologically sophisticated readers may have decided to take a walk, and that is a pity, for the book's strengths lie just ahead.

One strong feature is Freedman's crosscultural review of sex differences in the behaviour of human children. Cultural anthropologists have seldom standardized methodology or collected quantitative data, so the psychologist's touch is valuable here. Among the many interesting phenomena described are the prevalence of acknowledged hierarchies of "toughness" among small boys and the irrelevance of the same dimension for girls. Also intriguing are data on children's drawings, in which thematic sex differences are highly consistent across cultures even as substantial between-cultures variation is manifest.

Fifty student research projects carried out under Freedman's aegis (and outlined in a fifty-page appendix) are discussed in the text. Though highly variable in quality, these studies introduce a number of innovative methods and provocative findings. For example, modified TAT cards (pictures about which subjects are invited to tell a story) are used to assess the emotional impact and status significance of facial hair and of relative height, with results that sometimes contradict the respondents' professed attitudes. In a similar vein, the dimension of kinship is added to another standardized psychological instrument, Kohlberg's Moral Dilemmas, in order to provide evidence that people apply different moral codes to kin and non-kin. The use of such techniques should inspire readers interested in developing a sociobiological psychology.

The concluding chapter, entitled "Biology or culture?" begins with a not altogether successful attempt to dismiss such unproductive either-or-ism: "There is no way to separate the genetic and the learned for they are permanently glued together, and that is true everywhere in nature, including man". Heaven knows what is meant by "learning" if it is manifest "everywhere in nature", but most readers will probably find the sentiment acceptable if not the logic offered in support of it. Freedman then reviews his own convincing evidence for population differences in human infantile behaviour and temperament, proceeds to speculate plausibly that such differences may be causal to non-arbitrary cultural differences, and somehow concludes that racial "antagonisms are more or less built into the species" and that "the only sound solution lies in miscegenation"'. One is left perplexedly leafing back, vainly trying to reconstruct the extraordinary logic of this argument.

Robert Wallace's The Genesis Factor is blurbed as "the first popularly written book on sociobiology". If popular writing consists in talking down to one's readers and in disdaining to cite sources, the characterization is correct. Popular writing also apparently entails a suspension of respect for fact. Here are just three examples: parental care occurs in "only a few isolated species" of fishes (page 37); gorillas are "highly promiscuous"' (page 76); and the administration of androgens to infant female mice transforms them into killers without interfering with normal oestrus (page 116). Even where a particular experiment is under discussion, Wallace is liable to serious mis-statement of the results, as in his treatment of Harry Power's mountain bluebird removal experiments (page 179). Running roughshod over such disparate subjects as IQ and the alleged adaptive value of death, Wallace's book will regrettably reinforce antibiological prejudices of some social scientists while proving an embarrassment to thoughtful biologists. It ends on an even more remarkable note than Freedman's book, namely the author's personal foreign policy recommendations for the United States government! With friends like Wallace, sociobiology has no need of enemies.

Let us hope that we will see more and better empirical work of the sort initiated by Freedman. And may we have fewer grand statements of the policy implications of human sociobiology, at least until the discipline grows up a little.

Martin Daly is an Associate Professor of Psychology at McMaster University, Hamilton, Ontario.

\section{Orcadian heritage}

\section{Euan W. MacKie}

Investigations in Orkney. By Colin Renfrew. Pp.234. (Society of Antiquaries: London. Distributed by Thames and Hudson: London, 1979.) £20.

UNTIL the recent oil discoveries the Orkney Islands seemed remote from and peripheral to modern Britain, yet several times in the past they have been at the crossroads of important movements of people and influences. These usually came either up the western seaways from Atlantic Europe, like the stone tomb-builders of Neolithic times and elements among the inventors of the Iron Age tower-forts known as brochs, or, like the Norsemen and the Early Bronze Age Beaker people respectively, westwards from Scandinavia or north-westwards from the Low Countries or the eastern mainland of Britain. Like the churning cross-currents of the Pentland Firth, these genetic and cultural mixtures often produced periods of striking local developments in the islands. The sandstone of which these are formed provided ideal building material and some remarkable developments in drystone architecture resulted.

Archaeological research in Orkney has been sporadic in the past with long periods of inactivity, but the early 1970s saw a burst of new work by visiting excavators. Sites like the Neolithic dwellings at Skara Brae and Knap of Howar, the Pictish and Norse village at Buckquoy, the prehistoric and early historic settlement at Skaill and the Neolithic chambered tomb at Quanterness (the main subject of the book) were explored with modern techniques for the first time. Knowledge is still advancing rapidly through the efforts of a new the Scottish Development Department, the North of Scotland Archaeological Services Unit based at Finstown.

Professor Renfrew has long been concerned to explain in modern terms the dramatic changes visible in the prehistoric archaeological record, such as the appearance of the chambered burial mounds of Atlantic Europe at around $\mathbf{4 2 0 0}$ $B C$, and he favours hypotheses of indigenous development rather than any involving the diffusion in some way of ideas and skills from more advanced cultures. The radiocarbon dates for the earliest European chambered mounds have in any case shown them to be older than those of the Early Bronze Age in the Mediterranean world which were originally suggested as prototypes. Another aspect of this new approach is the interpretation of the tombs in terms of the kind of societies which built them and of the environment in Quanterness is the first in Orkney to have been investigated with these general problems in mind.

One example of the detailed mass of evidence collected may be cited. resident team of archaeologists financed by which these people existed. The cairn at 